The spinal column was extensively distorted; the distance of the promontory of the sacrum to the symphysis was two and a half inches, and the cavity of the pelvis was so small, that it was hardly' possible to reach the head of the child. The incision through the abdominal skin and linea alba was seven inches long; the child was extracted alive, and did well, but the mother died on the third day. The wound of the aterus was found very widely gaping.

Labour was bronght on prematurely in a person, in whom, on account of deformed pelvis, the head of the child had been perforated in a previous labour. The child being eight months old, sixteen inches in length, and five pounds in weight, appeared perfectly capable of having lived, but it unfortunately presented with the feet, and owing most likely to this circumstance, was born dead. The mother left the hospital on the ninth day.

In the case where three children were born at a birth, labour was very quick, lasting not more than ten minutes. All the children exhibited signs of retarded and incomplete development, and died within a short time after birth. The quantity of liquor amnii amounted to thirty-four pints; the common placenta, two pounds in weight, was eleven inches in diameter. The secretion of milk and the lochial flux were regular, and the mother was able to leave the hospital on the 20th day.-Gemeins. Feitschr. $f$. Geburtsk.

REPORT OF THE LYING-IX HOSPITAL AT HEIDELBERG, UNDER PROF. NAEGELE.

During the years 1825 and 1326,415 children were born, of which 199 were boys, and 216 girls. In 394 the iead, in 4 the face, in 15 the breech or feet, in cne the arm, and in another the shoulder presented; not more than two women died; 16 chil. dren were born dead, and 19 prematurely; out of which there were three abortions. In six cases twins were born. The forceps were applied in fifteen cases; in ten of which the contractions of the uterus were insufficient to expel the child; in three cases the operation was rendered necessary by the smallness of the pelvis; and, in two, by the prolapsus of the funis, the head pre. senting.

The operation of turning was performed three tmes; in one case where the shoulder, in another where the arm, and, in a third, where the funis prestnted; the last child only was saved.

Perforation was performed in a rachitic female, who, when brought into the institution, had been several days in labour. The head was forcibly pressed into the brim; after a very powerful contraction, the waters escaped, the head remaining immoveable; the pains suddenly ceased, and the patient complained of a violent burning pain in the belly, and a sensation of faintness; the countenance was pale, the pulse very small, and the extremities cold; perforation was immediately performed, and the child extracted; but the uterus did not contract, the belly swelled, and was very tender; the patient became very restless, vomited, \&c., and died on the same evening. On examination, the lower portion of the uterus was found ruptured to the extent of four inches; the abdominal cavity was filled with extravasated blood, and exhibited distinct signs of inflammation. The distance from the promontory of the sacrum, to the symphysis, was three inches.

In a case of yery small pelvis, labour was artificially brought on in the eighth month of gestation, with complete success.

In a young female, with very large pelvis, labour was unusually quick; when the head descended through the external genitals, violent hemorrhage ensued; the funis was twisted round the neck, and the body was born before it could be loosened. The um. bilical vessels were found extensively lacerated; one of the arteries being completely torn asunder, and the vein partially ruptured. The child was very pale, and asphyxiated, but soon after the ligature of the funis, restored to life.-Klinisthe Annal.

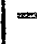

\section{ON SPINAL DEFORMITIES.}

By Dr. Harisison.

\section{To the Editor of THE LANCET.}

SrR,-Ever since my attention has been particularly drawn to the consideration of spinal deformity, and the complaints dependent upon it, I have been more and more convinced of the frequency of both, and of their injurious effects upon the health. So great is their prevalence, in this country at least, that I really believe not one female in twenty, above the condition of laborious servitude, remains wholly free from them. In proof of their tendency to undermine the constitution, it will be sufficient to add-1st. That where much deformity exists, the sufferer is disqualified from properly following any active employment; he is soon tired with labour, and obliged to desist from further exertion. 2diy. The great vessels, fastened internally to the spine, are unable freely to carry on the circulation through their contorted tubes; hence the vital fluid, preternaturally accumulated, encourages the formation of 
aneurisms in the arteries, and rarices in the veins. 3dly. 'The internal organs always suffer more or less in their functions, when the spine is distorted. The viscera, obliged to follow the irregular movements of the spine, are forced out of their natural situations, and, within the chest especially, are unduly squeezed and conpressed arainst the bonv covering. These several causes lay the foundation of numerous disorders, which operating at all times, generally destroy their victims prematurely.

Various and distressing as these maladies really are, they constitute only part of the heavy affictions, which the miaerable suferers are doomed to endure. From irregularities in the vertebral pillar, the cord and nerves issuing out of it, becoming unduly stretched, and pressed against the bony tubes, are rendered unfit, properly, to convey the nervous power, to its ultimate desti. nation. Many obstinate disorders owe their formation to the partial, or entire interruption, of the accustomed nervous supply. Their origin from this cause, and the remedies indicated, have, I conceive, been too generally mistaken, both by pathologists and practising physicians. They have been accustomed to trace its source to the brin as the fountain, whereas, in fact, it more commonly proceeds from the spine alone. So long as no efforts were made to relieve the defective arrangement of the vertebra, the offices of the spinal nerves could not be at all understood, and were, therefore, usually overlooked. Now that we have acquired the power of restoring the misshapen column to its primitive figure, these maladies are not only brought under review, but are subjected to a strict sureillance. No longer concealed from observation, they have, as already observed, been found in many instances to commence in the vertebral structure, and to abate as its derange. ment receded.

The power which I have successfully exercised over the spinal column for more than ten years, and which I challenge the most incredulous and prejudiced to contra. dict, has established a new era in medi. cine-an era which will soon lead to the most unexpected and tiserul results in practice. The authority of great names, and the infuence of high medical stations, may for a time retard, but cannot wholly arrest, its progress; it will, ultimately, surmount every obstacle, and triumph in def. ance of all opposition-magna est veritas, et mevalebit. Nay, 1 venture futher to assert, that this power over the spinal joints has already enabled me to cure several disorders deemed irremediable, and to cast a ray of light upon the most abstruse and difficult pathological questions. Equally misinformed are those medical practition- ers, whatever mav be their atthority of merit in other respects, who declare that recumbency, as now conducted in spinal complaints, tends to encourage bad lealth. These assertions are in direct opposition to multiplied experience. So great is our predilection for received tenets, and our obstinate attachment to current admissions, however erroneous, that several of the most violent declaimers against my prac. tice have actually attended patients to no good purpose, and, who remained for six or eight years, constantly lymg, and yet continued in good heal th during the whole time, The first and eighth cases in my treatise, besides that of Miss Goulding, published in lihe Gazette of Health, may be referred to, as confirmatory of this statement. So far then is recumbency from hurting the health, as mere theorists affect to believe, that, in these particular cases, it really conduces to its improvement, and frequently enables patients to subdue a phthisical habit, and other constitutional ailments.

According to the order laid down for pub. lishing my "Observations on Spinal Complaints," several cases, which I am anxious to make known early, would probably be de. ferred for several years. With a view to ob. viate this delay, I am desirous to print a select portion of them without further loss of time, that they may come under the imme. diate notice of my professional brethren. The accompanying case will be suceeded, at short intervals, by others, if it be deemed proper for insertion in your raluable pe. riodical.

$$
\begin{aligned}
& \text { I am, Sir, yours, \&c., } \\
& \text { EDward Harrson. }
\end{aligned}
$$

Holles Street, Cavendish Square, Jan. $20,18 \% 9$.

\section{A CASE OF PARAPLEGIA, CONPLICATED WITH FPILEPS, CURED BY APPLICA. TIONS TO THE SPRNA COLUMN.}

Sarah Tribet, in the twenty-second year of her age, of the sunguine temperament, and in good bodily health, had the misfortune to loze the feeling and motion of her lower ex. tremities, upwarts of three rears and a hall'since. Sensibility of the limbs returnet partially in six weeks, but they recorered none of their activity, and the feeling was agrain lost after a slourt time. She sars that her back and left side, a little below the ialse ros, have been rery tender, and in. capable of motion for nearly the same paiod. Pulse, bowels, and appetite, are tolerably regular. The menses observe their natural periods, and fow in moderate quantities, but are very dark-coloured, and hinhly offensive.

She traces her suffurings to haring exerted all her force to raise from the ground a 